\title{
Représentations des identités européennes
}

Ainsi que le remarque Manfred Pfister, " chaque description ou définition de l'autre culture implique une autodescription ou une autodéfinition. [...] Une culture se définit en définissant les autres cultures; le soi se définit en définissant l'autre. » (Pfister, $1996: 4)^{1}$. Les articles rassemblés dans ce troisième numéro de la revue Synergies Canada examinent comment l'identité européenne a été et continue d'être représentée dans les arts visuels, en littérature, ainsi que dans des produits culturels plus récents, telles les légendes urbaines. Ils analysent surtout les autoreprésentations européennes mais aussi quelques représentations proposées par d'autres, « autres » qui se situent à l'intérieur ou à l'extérieur de l'entité qui est l'Europe.

Dans l'article inaugural, Fanny Robles (Université de Toulouse) étudie les représentations de groupes d'individus provenant des régions récemment colonisées par les grandes puissances européennes lors des spectacles ethnographiques qui étaient populaires en Europe à la fin du dix-neuvième siècle. À travers des représentations littéraires et dans les arts visuels, cet article tente de cerner les types de consommation que ces productions culturelles suscitent. Dans son article « Visions et représentations d'une Europe unifiée à la veille de la Première Guerre mondiale, dans Jean-Christophe de Romain Rolland » Sarah Katrib (Université de Strasbourg) s'attarde sur ce célèbre roman-fleuve pacifiste qui propose l'image d'une Europe unifiée par ses créations musicales et littéraires.

Les trois articles qui suivent examinent différentes facettes du surréalisme européen. En identifiant trois moments qui constituent de « grands écarts identitaires » pour le surréalisme français, Jacqueline Chenieux-Gendron (CNRS) analyse le développement de la politique et de l'esthétique de ce groupe. Monique Yaari (The Pennsylvania State University) examine, pour sa part, un moment clé dans l'histoire du surréalisme international. II s'agit de la rupture, d'une part, entre le groupe surréaliste de Bucharest et le peintre surréaliste belge René Magritte et, d'autre part, entre André Breton et Magritte. C'est encore le surréalisme roumain qui est l'objet de l'article de lulian Toma (Université McMaster) qui, à travers une étude de l'œuvre inédite et publiée de Gherasim Luca, repère des références qui nous permettent de mieux comprendre la signification de l'Holocauste pour ce poète.

Le numéro se termine avec une analyse des légendes urbaines contemporaines, circulées surtout sur Internet. Aurore Van de Winkel (Université Catholique de Louvain) interprète celles-ci comme des récits qui construisent et proposent une conception de l'identité européenne en réaffirmant certaines normes et valeurs et en s'opposant à d'autres. La construction identitaire qui découle de la confrontation avec l'autre est donc au centre de la problématique de chacun des articles rassemblés dans ce volume. Qu'elle ait lieu à la fin du dix-neuvième siècle ou à la période contemporaine, dans un produit culturel populaire ou d'élite, l'autodéfinition dépend du regard de l'autre.

Les articles de ce volume ont d'abord été présentés, sous une autre forme, lors du colloque international «Europe in its own eyes / Europe in the eyes of the other » qui a eu lieu à l'Université de Guelph (Ontario, Canada) du 1-3 octobre 2010. Ce colloque avait pour but d'examiner comment les identités européennes se forment, perdurent en dépit d'existences parfois fragiles et contradictoires ou fissurent, déstabilisées par les événements historiques du passé lointain ou plus récent. II visait à encourager la recherche en études européennes et à promouvoir les contacts et échanges entre chercheurs canadiens et étrangers. Des concepts interdisciplinaires tels que l'autre / le soi, le centre /la périphérie et l'inclusion /l'exclusion ont été évoqués pour comprendre comment des idées concernant l'individualité, la nation et l'Europe encouragent la création, la contestation et la mutation d'identités. D'autres articles provenant du colloque paraîtront dans un numéro du Journal of European Studies. Un volume aux Presses de l'Université de Wilfrid Laurier est aussi en préparation.

Comme toujours, nous tenons à remercier nos assistants à la rédaction, Brandon Carroll et Jessica Martin, ainsi que Wayne Johnston pour sa patience et son soutien avec la plateforme OJS.

Margot Irvine, Frédérique Arroyas et Éliane Lousada

\footnotetext{
${ }^{1}$ « ... each descripion or definition of the other culture implies a self-description or self-definition [...]. A culture defines itself by defining other cultures ; the self defines itself by defining the other. » La traduction française est la nôtre.
}

\section{Bibliographie}

PfISTER, Manfred. (1996). "Introduction". The Fatal Gift of Beauty: The Italies of British Travellers: An Annotated Anthology. Manfred Pfister, ed. Amsterdam, Atlanta: Rodopi. 2-21. 